\title{
Compactação ruminoabomasal decorrente da ingestão de caule de bananeira (Musa sp.) em bovinos: relato de dois casos
}

\author{
Rumen-abomasal impaction caused by eating banana stem (Musa sp.) \\ In cattle: report of two cases
} Michel Abdalla Helayel, ${ }^{*}$ Adriano Tony Ramos, ${ }^{* *}$ Fabiano Mendes de Cordova, ${ }^{* *}$ Marco Augusto Giannoccaro da Silva, ${ }^{* * *}$
Antônio José Sabino, ${ }^{* * * *}$ Francisberto Batista Barbosa, ${ }^{* * * * *}$ Sandro Estevan Moron, ${ }^{* * * * *}$ Leonardo Vaz Burns ${ }^{* * * * * *}$

\begin{abstract}
Resumo
A compactação dos pré-estômagos é um transtorno digestório pouco frequente. E pode ter origem primária ou secundária. Os autores descrevem o primeiro relato de compactação ruminoabomasal causado pela ingestão de caule de bananeira (Musa sp.) em bovinos. Os casos ocorreram em duas vacas, mestiças de aptidão leiteira, com idades de 5 e 4 anos respectivamente, oriundas de uma propriedade rural no município de Araguaína, Estado do Tocantins (TO). O histórico, os achados clínicos, os resultados dos exames hematológicos e a análise do fluido ruminal permitiram o diagnóstico, que foram confirmados por necropsia e laparotomia exploratória. O uso de caule de bananeira (Musa sp.) como única fonte de volumoso favoreceu a ocorrência da compactação ruminoabomasal. No entanto, essa fonte de alimento pode ser considerada uma boa opção para a alimentação de bovinos, desde que seja fornecido em proporções adequadas na dieta.
\end{abstract}

Palavras-chave: bovinos, compactação, clínica, ruminotomia, sistema digestório.

\begin{abstract}
The pre-stomach impaction is a rare digestive disorder. And can be primary or secondary origin. The authors describe the first report of impaction rumino-abomasal caused by eating stalk of banana (Musa sp.) In cattle. The cases occurred in two crossbred dairy cows, aged 5 and 4 years respectively, originated from a farm in the municipality of Araguaína, Tocantins (TO). The history, clinical findings, results of blood tests and analysis of rumen fluid led to diagnosis of compression of the rumen and abomasums, which were confirmed by necropsy and exploratory laparotomy. The use of stem of banana (Musa sp.) as the only source of forage favored the occurrence of impaction rumino-abomasal. However, this food source can be considered a good choice for cattle feed, from which is provided in adequate proportions in the diet.
\end{abstract}

Keywords: cattle, impaction, clinical ruminotomy, digestive system.

\section{Introdução}

A compactação dos pré-estômagos é um transtorno digestório pouco frequente (Moscardini e Borges, 2007). E pode ter origem primária, que se dá pela ingestão de forragem de baixa qualidade, ricas em lignina e com baixos níveis de energia e proteína digerível, associada ou não a restrição hídrica (Blikslager et al., 1993; Moscardini e Borges, 2007; Borges et al., 2007). Casos de compactação primária têm sido relatados devido à ingestão excessiva de areia ou cascalho e utilização de alimentos não usuais, como cascas de amêndoas (Purohit et al. 1987; Mitchell, 1991; Cebra et al., 1996; Melendez et al., 2007), cascas de feijão (Phaseolusvulgaris e Vignaunguiculata) e folhas de oiticica (Licaniarigida) (Assis et al., 2009). Já as causas secundárias incluem distúrbios de escoamento pilórico devido a lesões nos ramos ventrais do nervo vago, dano vascular ou neurogênico secundário a vólvulo abomasal, além de obstruções intraluminais, murais e extraluminais (Blikslager et al., 1993; Smith, 1993; Trent, 2004), colocação imprópria de suturas "às cegas" (método "toggle"), omentopexia ou piloropexia e compressão pilórica pelo útero gravídico, principalmente no trimestre final de gestação (Kelton e Fubini, 1989; Saint Jean e Anderson, 1999; Whitlock, 1999).

Dessa forma, a capacidade da microbiota do rúmen em reduzir o tamanho das partículas ingeridas fica comprometida, com o

\footnotetext{
* Clínica Médica de Ruminantes da Escola de Medicina Veterinária e Zootecnia - Medicina Veterinária da Universidade Federal do Tocantins. Br. 153, Km 112, cx postal 132. Araguaína - TO. CEP 77804970. Autor para correspondência: E-mail: michel_abdallavet@yahoo.com.br.

** Anatomia Patológica da Escola de Medicina Veterinária e Zootecnia - Medicina Veterinária da Universidade Federal o Tocantins.

*** Clínica Médica de Equídeos da Escola de Medicina Veterinária e Zootecnia - Medicina Veterinária da Universidade Federal do Tocantins.

**** Médico Veterinário autônomo. Palmas - TO.

${ }^{* * * * *}$ Escola de Medicina Veterinária e Zootecnia, graduando em Medicina Veterinária - Universidade Federal do Tocantins (UFT), Araguaína, Tocantins, Brasil.

****** Laboratório de morfologia e bioquímica, Escola de Medicina Veterinária e Zootecnia - Medicina Veterinária da Universidade Federal do Tocantins.

*******Hospital Veterinário da Escola de Medicina Veterinária e Zootecnia - Medicina Veterinária da Universidade Federal do Tocantins
} 
alimento acumulando-se nos pré-estômagos, obstruindo a luz visceral e não possibilitando a progressão da ingesta que se transforma em uma massa compacta de material indigerível (Mitchell, 1991).

Os principais sinais clínicos são: anorexia, desidratação, timpanismo, hipotonia ou atonia ruminal, distensão abdominal, fezes escassas ou ausentes, e às vezes recobertas de muco (Radostits et al., 2000; Garry, 2002). A análise do fluido ruminal revela, na maioria dos casos, o comprometimento da atividade da fauna e flora (Dirksen et al., 1993; Garry, 2002). Na patologia clínica são relatadas alterações compatíveis com quadros de desidratação, leucocitose por neutrofilia com desvio para esquerda regenerativo e hiperfibrinogenia (Afonso et al., 2008).

O tratamento depende da gravidade e da cronicidade da compactação, e pode ser clínico: correção do desequilíbrio hídrico-eletrolítico e acidobásico, administração de agentes emolientes e laxativos, como sementes de linhaça cozidas (500g em $10 \mathrm{~L}$ de água) e sulfato de $\mathrm{Mg}(1 \mathrm{~kg})$ em 10 litros de água morna, administrada por via oral, através de sonda orogástrica; ou cirúrgico; ruminotomia para retirada do excesso de conteúdo ruminal compactado e reposição da microbita através da colocação de conteúdo ruminal fresco de outro bovino saudável (Afonso e Borges, 2007; Riet-Correa et al., 2007). O prognóstico geralmente é reservado, principalmente em animais com gestação avançada (Garry, 2002).

Com este estudo os autores descrevem o primeiro relato de compactação de rúmen e abomaso causado pela ingestão de caule de bananeira (Musa sp.), em dois bovinos de uma propriedade rural no município de Araguaína, estado do Tocantins.

\section{Relato de caso}

Os casos ocorreram em uma propriedade rural localizada no município de Araguaína, TO, com rebanho total formado por 5 bovinos jovens e 25 bovinos adultos, sendo 2 machos e 23 fêmeas, todos mestiços de aptidão leiteira. Devido à grande degradação dos pastos da propriedade pelo período de seca prolongado na região, todos os bovinos da propriedade recebiam dieta composta por 80 a $90 \%$ de caule de bananeiras que eram previamente cortados com facão (Figuras 1 e 2).

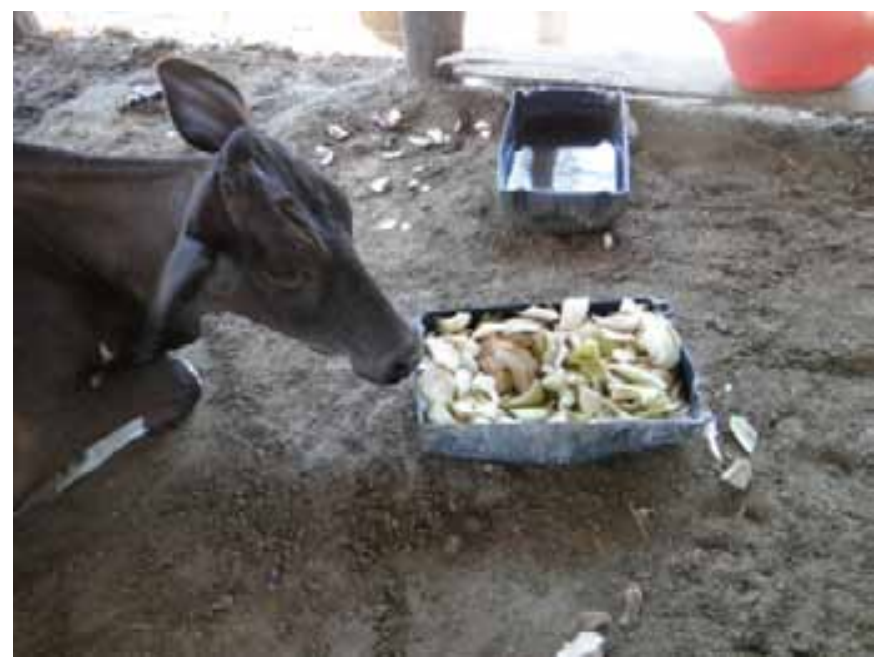

Apenas dois animais identificados como animal A e B, ambos fêmeas e com idades de 5 e 4 anos, respectivamente, desenvolveram a enfermidade. $O$ animal A estava recém- -parida e o B encontrava-se com 7 meses de gestação. Os casos foram considerados graves devido à presença de distensão abdominal e compactação do rúmen. Foi a primeira ocorrência da doença na propriedade.

Os animais foram examinados clinicamente seguindo as recomendações de Dirksen et al. (1993). Foram coletadas amostras sanguíneas dos dois animais em tubo a vácuo com anticoagulante EDTA (10\%) e sem anticoagulante, para realização de hemograma e análise bioquímica dos teores séricos de alanina aminotransferase (ALT), aspartato aminotransferase (AST), gamaglutamiltransferase (GGT), creatinofosfoquinase (CPK), ureia, creatinina e fibrinogênio conforme (Jain, 1993). Amostras de fluido ruminal foram coletadas e analisadas de acordo com Dirksen et al. (1993). Nos dois casos, o suco ruminal apresentou coloração verde acastanhado; odor sui generis; consistência aquosa e $\mathrm{pH}$ 7,0 e 8,0 nos animais $\mathrm{A}$ e $\mathrm{B}$, respectivamente. Os testes de sedimentação e flutuação foram negativos; os testes de redução do azul de metileno indicaram tempos maiores que 10 minutos; e raros protozoários foram observados (Figura 3).

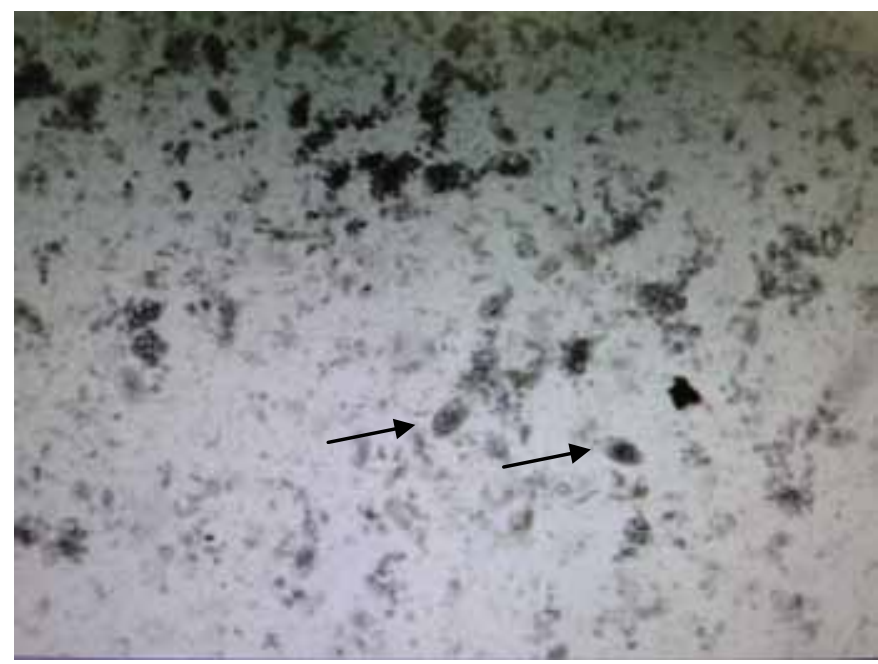

Figura 3: Raros protozoários observados no suco ruminal, obj. 40x.

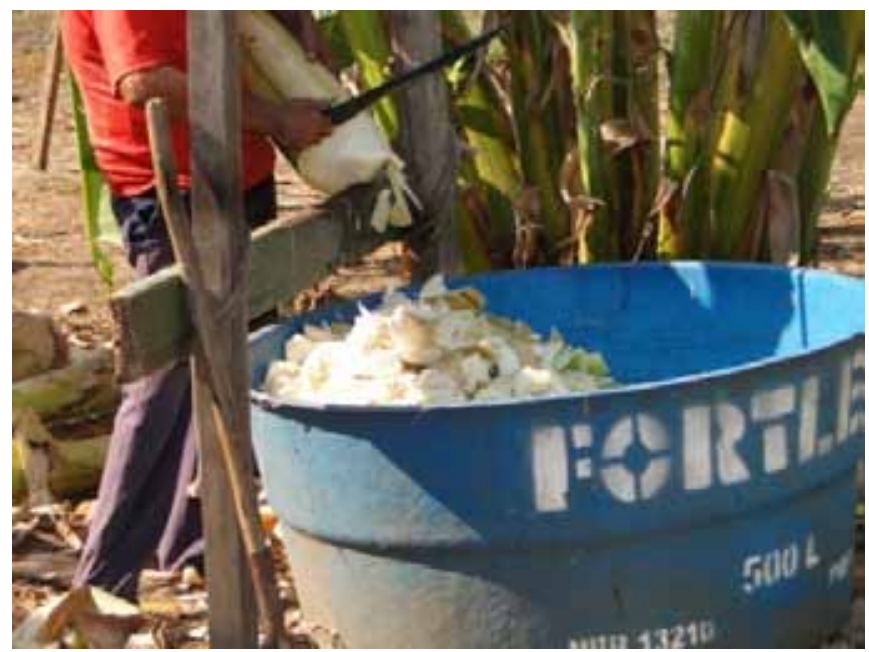

Figuras 1 e 2: Bovino recebendo no cocho dieta composta por 80 a 90\% de caule de bananeira, previamente cortadas com facão. 
O diagnóstico presuntivo de compactação de rúmen e abomaso foi dado a partir dos dados epidemiológicos, sinais clínicos e avaliação do suco ruminal.

Imediatamente após o diagnóstico, foi instaurado o tratamento clínico nos dois animais. O tratamento inicial constituiu em fluidoterapia intravenosa (IV) para correção do desequilíbrio hídrico-eletrolítico e acidobásico; e substâncias laxativas, como sementes de linhaça cozidas ( $500 \mathrm{~g}$ em $10 \mathrm{~L}$ de água) e sulfato de $\mathrm{Mg}(1 \mathrm{~kg})$ em 10 litros de água morna, administradas através de sonda orogástrica. No dia seguinte, o animal A veio a óbito e foi necropsiado. O animal $B$ foi sedado com medicação préanestésica (MPA), à base de $0,04 \mathrm{mg} / \mathrm{kg}$ de xilazina (Rompum - Bayer Saúde Animal - São Paulo, Brasil) e 0,2mg/kg de acepromazina (Acepran - VETNIL - Louveira, Brasil) por via intravenosa, associado a anestesia regional paravertebral, segundo (Muir et al., 2001); e imediatamente submetido à cirurgia de laparotomia exploratória pelo flanco esquerdo, seguida de ruminotomia, segundo (Turner e Mcilwraith, 2002), com o animal em posição quadrupedal, com subsequente retirada da ingesta e infusão de sementes de linhaça cozidas $(500 \mathrm{~g}$ em $10 \mathrm{~L}$ de água), sulfato de $\mathrm{Mg}(1 \mathrm{~kg})$, capim fresco e 10 litros de suco ruminal (transfaunação). O pós-operatório instituído foi composto por oxitetraciclina (Tetradur LA 300 - Merial - Paulínia, Brasil) na dose de $20 \mathrm{mg} / \mathrm{kg}$, por via intramuscular, a cada 72 horas, por cinco dias, flunixin meglumine (Desflan - Ouro Fino saúde Animal - Cravinhos , Brasil), na dose de 1,1 mg/kg, por via intramuscular, a cada 24 horas, por cinco dias e fornecimento de forragem (Panicum maximum cv. Mombaça) de boa qualidade, com cortes de $10 \mathrm{~cm}$ e água ad Libitum. Também foi recomendado que o animal fosse estimulado a caminhar por 20 minutos a cada 1 hora. $O$ animal $B$ veio a óbito $48 \mathrm{~h}$ após a cirurgia, sendo também submetido à necropsia.

Na necropsia do animal A o abomaso encontrava-se aumentado de volume e com conteúdo alimentar muito compactado. Adicionalmente, também foram observados compactação rumino-abomasal e pequenas áreas de hiperemia nas mucosas do rúmen, omaso e abomaso, intestinos com muco e pouco conteúdo de ingesta. Na necropsia do animal B foi observado quadro macroscópico de peritonite fibrinopurulenta difusa, grande quantidade de material compactado no omaso e abomaso, e intestino com muco e pouco conteúdo.

Os dados epidemiológicos, evolução clínica, conduta terapêutica e resolução clínica dos casos estão resumidos na Tabela 1.

Os principais resultados dos exames clínicos estão apresentados na Tabela 2. Os achados do hemograma e bioquímica sérica são mostrados na Tabela 3.
O diagnóstico foi confirmado pela necropsia do animal A e laparotomia exploratória do animal B.

\section{Discussão}

A compactação primária do abomaso ocorreu associada à compactação de rúmen, nos dois casos relatados no trabalho. Esse tipo de distúrbio se dá pela ingestão de forragem de baixa qualidade, ricas em lignina e com baixos níveis de energia e proteína digerível (Blikslager et al., 1993; Moscardini e Borges, 2007; Borges et al., 2007), já sendo relatados casos devidos à utilização de alimentos não usuais (Purohit et al. 1987, Mitchell 1991, Cebra et al. 1996, Melendez et al. 2007, Assis et al., 2009).

Ambos os casos foram causados pela quantidade excessiva de talo de bananeira (Musa sp.) na dieta, bem como pelo tempo prolongado de sua utilização. Pois níveis elevados (acima de 70\%) de bananeira (folha ou caule) na dieta elevam os teores de extrato etéreo (acima 6\%), o que promove a diminuição na digestibilidade da fibra (Van Soest, 1994), seja pelo efeito tóxico sobre organismos celulolíticos, ou como consequência há diminuição da flora ruminal (Henderson, 1973). O excesso de taninos contidos nesse subproduto reduz a digestibilidade da matéria seca (MS) por causar efeitos bactericidas e bacteriostáticos na microbiota ruminal (Henis et al., 1964), redução no número total e na variedade de gêneros de protozoários ciliados do rúmen (Silva et al., 2006), e ainda por interagir com a proteína da dieta para formar complexos tanino-proteína indigeríveis (Kumar e Singh, 1984), produzindo assim maiores percentuais de nitrogênio indigerível em detergente ácido (NIDA). Esse fator pode ser limitante para a digestão dos nutrientes, visto que indisponibiliza o nitrogênio para os micro-organismos ruminais, o que retarda o crescimento das bactérias ruminais fermentadoras de fibra, bem como a produção dos complexos enzimáticos responsáveis pela despolimerização dos carboidratos fibrosos, deprimindo a capacidade de digestão (Van soest, 1994).

Os sinais clínicos observados foram semelhantes aos explanados na literatura (Braun et al.,1990; Mitchell, 1991; Blikslager et al., 1993; Hoffsis e Mcguirk, 1993; Smith, 1993; Simkins e Nagele, 1997; Saint Jean e Anderson, 1999; Moscardini e Borges, 2007; Borges et al.,2007; Radostits et al., 2007; Câmara et al., 2009), e consistiam na presença de estrutura compactada no abdômen médio e ventral, esquerdo e direito, e na identificação de sons com características de macicez ampla a absoluta na percussão da região.

As alterações hematológicas consistiram de leucocitose por neutrofilia e hiperfibrinogenemia, alterações que sugerem processo inflamatório agudo no local da obstrução (Cole

Tabela 1: Dados epidemiológicos, evolução clínica, conduta terapêutica e resolução clínica dos dois bovinos com compactação de rúmen e abomaso no Município de Araguaína, TO

\begin{tabular}{|c|c|c|c|c|c|c|c|c|c|}
\hline Bovino & Idade & $\operatorname{Sexo}^{a}$ & $\begin{array}{l}\text { Fase de } \\
\text { produção }\end{array}$ & Alimentação & $\begin{array}{l}\text { Tempo de } \\
\text { ingestão }\end{array}$ & $\begin{array}{l}\text { Mês de } \\
\text { ocorrência }\end{array}$ & $\begin{array}{l}\text { Evolução } \\
\text { Clínicab }^{b}\end{array}$ & $\begin{array}{c}\text { Conduta } \\
\text { terapêutica }\end{array}$ & Resolução \\
\hline A & 5 anos & $F$ & $\begin{array}{c}\text { Gestante } 7 \\
\text { meses }\end{array}$ & $\begin{array}{l}80 \text { a } 90 \% \text { de caule de bana- } \\
\text { neira cortado com facão, Bra- } \\
\text { chiaria decumbens }\end{array}$ & 4 meses & 09/seca & 7 dias & Clínica & Morte \\
\hline B & 4 anos & $F$ & $\begin{array}{l}\text { Recém } \\
\text { parida }\end{array}$ & $\begin{array}{l}80 \text { a } 90 \% \text { de caule de bana- } \\
\text { neira, Brachiaria decumbens }\end{array}$ & 4 meses & 09/seca & 10 dias & $\begin{array}{l}\text { Clínica e } \\
\text { cirúrgica }\end{array}$ & Morte \\
\hline
\end{tabular}

a: $F$ = fêmea.

b: Dias após o início dos sinais clínicos observados pelos proprietários ou tratadores. 
Tabela 2: Dados do exame clínico dos dois bovinos com compactação de rúmen e abomaso no Município de Araguaína, TO

\begin{tabular}{|c|c|c|}
\hline \multirow{2}{*}{ Parâmetros* } & \multicolumn{2}{|c|}{ Achados clínicos } \\
\hline & Animal A & Animal B \\
\hline Comportamento & Apático & calmo \\
\hline Escore Corporal & II & IV \\
\hline $\begin{array}{l}\text { Grau desidrata- } \\
\text { ção }\end{array}$ & 10 & 8 \\
\hline Enoftalmia & Presente & Discreta \\
\hline Apetite & Ausente & Ausente \\
\hline Temperatura ${ }^{\circ} \mathrm{C}$ & Aumentada (39.3) & Normal (38.8) \\
\hline $\begin{array}{l}\text { Frequência cardí- } \\
\text { aca (Movimentos/ } \\
\text { minuto) }\end{array}$ & $\begin{array}{l}\text { Aumento moderado } \\
\text { (86) }\end{array}$ & Normal (80) \\
\hline $\begin{array}{l}\text { Frequência respi- } \\
\text { ratória (Batimen- } \\
\text { tos/minuto) }\end{array}$ & Aumentada (49) & Leve aumento (40) \\
\hline Motilidade ruminal & Ausente & Ausente \\
\hline Tensão abdominal & Aumentada & Aumentada \\
\hline $\begin{array}{l}\text { Palpação abdo- } \\
\text { minal }\end{array}$ & $\begin{array}{c}\text { Presença de estrutura } \\
\text { compactada }\end{array}$ & $\begin{array}{c}\text { Presença de estrutura } \\
\text { compactada }\end{array}$ \\
\hline Palpação retal & $\begin{array}{l}\text { Sem anormalidades } \\
\text { palpáveis }\end{array}$ & $\begin{array}{l}\text { Sem anormalidades } \\
\text { palpáveis }\end{array}$ \\
\hline Fezes & $\begin{array}{c}\text { Escassa, presença de } \\
\text { muco }\end{array}$ & $\begin{array}{c}\text { Escassas, presença } \\
\text { de muco }\end{array}$ \\
\hline Mucosas & Hipocoradas & Hipocoradas \\
\hline $\begin{array}{l}\text { Tempo de preen- } \\
\text { chimento capilar } \\
\text { (segundos) }\end{array}$ & Aumentado (4) & Aumentado (4) \\
\hline $\begin{array}{l}\text { Percussão do } \\
\text { abdômen }\end{array}$ & $\begin{array}{c}\text { Anormal (Parte media } \\
\text { e ventral com macicez } \\
\text { ampla a absoluta) }\end{array}$ & $\begin{array}{c}\text { Anormal (Parte media } \\
\text { e ventral com macicez } \\
\text { ampla a absoluta) }\end{array}$ \\
\hline
\end{tabular}

*Dados comparativos segundo Dirksen et al. (1993).
Tabela 3: Achados do hemograma e bioquímica sérica dos dois bovinos com compactação de rúmen e abomaso no Município de Araguaína, TO

\begin{tabular}{|c|c|c|c|}
\hline \multirow{2}{*}{ Parâmetros } & \multicolumn{2}{|c|}{ Achados clínicos } & \multirow{2}{*}{$\begin{array}{l}\text { Valores de } \\
\text { referência* }\end{array}$} \\
\hline & Animal A & Animal B & \\
\hline Eritrócito $\left(\times 10^{6} / \mu \mathrm{L}\right)$ & 5,10 & 7,0 & $5,0-8,0$ \\
\hline Hematócrito (\%) & 34 & 33 & $26-42$ \\
\hline Hemoglobina (g/dL) & 11,2 & 10,8 & $8,0-14,0$ \\
\hline VCM (fL) & 64 & 45 & $37-54$ \\
\hline $\mathrm{CHCM}(\%)$ & 29 & 32 & $26-36$ \\
\hline PPT (g/dL) & 9.9 & 9,5 & $6,7-7,5$ \\
\hline Fibrinogênio (mg/dL) & 1000 & 800 & $200-500$ \\
\hline Leucócitos totais $\left(\times 10^{3} / \mu \mathrm{L}\right)$ & 10000 & 9300 & $4,1-12$ \\
\hline $\begin{array}{l}\text { Netrófilos segmentados } \\
\qquad\left(\times 10^{3} / \mu \mathrm{L}\right)\end{array}$ & 4,5 & 3,8 & $1,5-5,0$ \\
\hline Bastonetes $\left(\times 10^{3} / \mu \mathrm{L}\right)$ & 00 & 00 & $0,0-0,19$ \\
\hline Linfócitos $\left(\times 10^{3} / \mu \mathrm{L}\right)$ & 4,0 & 5,5 & $3,0-7,5$ \\
\hline 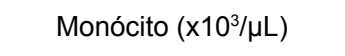 & 0,3 & 0,4 & $0,1-1,5$ \\
\hline Eosinófilos $\left(x 10^{3} / \mu \mathrm{L}\right)$ & 0,1 & 0,3 & $0,1-1,5$ \\
\hline 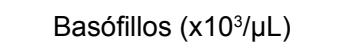 & 00 & 00 & Raros \\
\hline ALT (UI/L) & 20 & 18 & $14-38$ \\
\hline AST (UI/L) & 94 & 120 & $78-132$ \\
\hline GGT (UI/L) & 17 & 20 & $11-24$ \\
\hline CK (UI/L) & 88 & 110 & $66-120$ \\
\hline Uréia (mg/dL) & 22 & 25 & $20-30$ \\
\hline Creatinina (mg/dL) & 1,2 & 1,7 & $1-2,0$ \\
\hline
\end{tabular}

${ }^{*}$ Meyer, Coles e Rich (1995) 
et al., 1997; Morris e Johnston, 2006), ou um possível comprometimento da parede do rúmen e/ou abomaso. Tais alterações são consideradas comuns em alguns tipos de distúrbios obstrutivos no trato gastroentérico dos ruminantes (Radostits et al., 2007; Afonso et al., 2008).

As amostras de fluido ruminal analisadas apresentaram coloração esverdeada, de acordo com as características macroscópicas dos ingredientes da dieta dos bovinos (Dirksen et al., 1993). $\mathrm{O}$ odor apresentou-se alterado, com comprometimento da microbiota ruminal, fato evidenciado através da prova de redução do azul de metileno, do teste de sedimentação e flutuação e acentuada diminuição da atividade dos protozoários.

Tais achados são justificados pela estase ruminal (Dirksen et al., 1993). Acredita-se que a consistência e pH observados nos fluidos ruminais são decorrentes da anorexia,da dinâmica digestiva diminuída e, consequente, putrefação do conteúdo (Dirksen et al., 1993).

A associação do histórico com os achados clínicos, resultado dos exames hematológicos e análise do fluido ruminal permitiram o diagnóstico de compactação de rúmen e abomaso, que foram confirmados pela necropsia no animal A (Jones et al.,

\section{Agradecimentos}

À Merial, pelo apoio dado aos nossos trabalhos.

\section{Referências}

AFONSO,J.A.B.; BORGES,J.R.J. Compactação de rúmen In: RIETCORREA, F.;SCHILD, A.L.;LEMOS,R.A.A.; BORGES,J.R.J.(Eds.), Doenças de Ruminantes e Eqüídeos. 3. ed. Santa Maria: Palotti, 2007, v. 2, p. 319-322.

AFONSO, J.A.B.; PEREIRA, A.L.L.; VIEIRA, A.C.; MENDONÇA, C.L.; COSTA,N.A .; SOUZAM, I. Alterações clínicas e laboratoriais na obstrução gastrintestinal por fitobezoários em bovinos. Revista Brasileira de Saúde e Produção Animal, v. 9, n. 1, p. 91-102, 2008. ASSIS, T.S.; MEDEIROS, R.M.T.; ARAÚJO, J.A.S.; DANTAS, A.F.M.; RIET-CORREA F. Intoxicações por plantas em ruminantes e eqüídeos no Sertão Paraibano. Pesq. Vet. Bras. v. 29, n. 11, p. 919-924, 2009.

BLIKSLAGER, A.T.;BRISTOL,D.G.; HUNTE.L. Abomasal impaction incattle. Compendium, v. 15, n.11, p. 1571-1575, 1993.

BORGES, J.R.J.; CUNHA, P.H.J.;MOSCARDINI, A.R.C.; FRANCO,G.L.; SILVA,L.A.F. Compactação de abomaso em bovinos leiteiros: descriçãode cinco casos. Ciência Anim. Bras., v. 8, n. 4, p. 859-864, 2007.

BRAUN, U.; STEINER, A.; KAEGI, B. Clinicalhaematological andbiochemical findings and the results of treatment in cattle with acutefunctional pyloric stenosis. Vet. Rec., v. 3, n. 1, p. 107-110, 1990.

Câmara, A.C.L.; Afonso, J.A.B.; Costa, N.A.; Mendonça, C.L.; Souza, M.I. Compactação primária do abomaso em 14 bovinos no Estado de Pernambuco. Pesq. Vet. Bras. v. 29, n. 5, p. 387-394, 2009.

CEBRA, C.K.;CEBRA,M.L.; GARRY,F.B. Gravel obstruction in theabomasum or duodenum of two cows.J. Am. Vet. Med. Assoc., v. 209, n. 7, p.1294-1296, 1996.

COLE, D.J.;ROUSSEL,A.J.; WHITNEY, H.S. Interpreting a bovine CBC:Evaluating the leukon and acute phase proteins. Vet. Med., v. 92, n.1, p. 470-78, 1997.
2000) e pela laparotomia exploratória no animal B (Braun et al., 1990; Simkins e Nagele, 1997; Wittek et al., 2005; Borges et al., 2007).

No relato dos casos em questão os dois animais vieram a óbito, sem sucesso terapêutico e cirúrgico, conforme já citado na literatura por outros autores (Mitchell 1991; Borges et al. 2007) e (Simkins e Nagele 1997; Borges et al. 2007) respectivamente. Alguns autores relatam índices de recuperação próximos a 50\% (Wittek et al., 2005; Câmara et al., 2009). E que a resposta ao tratamento depende da severidade dos casos (Saint Jean e Anderson,1999), associado ao grau de compactação do abomaso e demais pré-estômagos (omaso e rúmen), sendo ainda mais reservado nos casos de gestação avançada e pósparto imediato (Câmara et al., 2009).

\section{Conclusões}

No presente estudo, o uso de talo de bananeira (Musa sp.) como única fonte de volumoso favoreceu a ocorrência da compactação ruminoabomasal. No entanto, essa fonte de alimento pode ser considerada uma boa opção para a alimentação de bovinos, desde que seja fornecido em proporções adequadas na dieta.

DIRKSEN G., GRÜNDERH.D.; STÖBER M. Rosenberger, Exame Clínico dos Bovinos. 3. ed. Rio de Janeiro: Guanabara Koogan, 1993. 419 p.

GARRY, F. B. Inactivity of rumen microbial flora. In: SMITH, B. P. (Ed.). Large animal internal medicine. 3. ed. St. Louis: Mosby, 2002. p. 722-731.

HENDERSON, C. The effects of fatty acid on pures cultures of rumen bacteria. Journal of Agriculture Science, v. 81, p. 107-112, 1973.

HENIS, Y.; TAGARI, H.; VOLCANI, R. Effect of water extract of carob pods tannic acid and their derivaties on the morphology and growth of micro-organisms. Appl.

Microbiology. v.12, p. 204-211, 1964.

HOFFSIS,G.F.; MC GUIRK,S.M. Abomasal impactions in cattle. In: HOWARD, J.L.; SMITH, R.A. (Eds.). Current Veterinary Therapy: Food animal practice. Philadelphia: W.B. Saunders, 1993. v. 1, p. 732-733.

JAIN, N.C. Essentials of Veterinary Hematology. Philadelphia: Lea \& Febinger, 1993. $417 \mathrm{p}$.

JONES, T.C.; HUNT, R.D.; KING, N.W. Patologia Veterinária. 6. ed. Barueri, São Paulo: Editora Manole, 2000, 1415 p.

KELTON, D.F.; FUBINI, S.L. Pyloric obstruction after toggle pin fixation nof left displaced abomasum in a cow. J. Am. Vet. Med. Assoc., v.194, n. 1, p. 677-678, 1989.

KUMAR, R.; SINGH, M. Tannins: Their adverse role in ruminant nutrition. J. Agric. Food. Chem., v. 32, p. 447-453, 1984.

MELENDEZ, P.; KRUEGER, T.;BENZAQUEN, M.; RISCO, C.An outbreakof sand impaction in postpartum dairy cows. Can. Vet. J., v. 48, n.1, p.1067-1070, 2007.

MEYER, D.J.; COLES, E.H.; RICH, L.J. Medicia de laboratório veterinária: Interpretação e diagnóstico. São Paulo: Roca, 1995, $308 \mathrm{p}$. 
MITCHELL, K. Dietary abomasal impaction in a herd of dairyreplacement heifers.J. Am. Vet. Med. Assoc., v.198, n.8, p.1408-1409, 1991.

MORRIS,D.D.; JONSTON, J.K. Alterações nas proteínas do sangue. In: SMITH,B.P. (Ed.).Tratado de Medicina Interna de GrandesAnimais. 3. ed. São Paulo: Manole, 2006. p. 427-433.

MOSCARDINI,A.R.C.; BORGES,J.R.J. Compactação de abomaso. In: RIET-CORREA, F.;SCHILD,A.L.;LEMOLS,R.A.A. \&BORGES,J.R.J. (Eds.). Doenças de Ruminantes e Eqüídeos. 3. ed. Santa Maria: Palotti, 2007. v. 2, p. 352-355.

MUIR, W.W.; HUBBE, J.A.E.; SKARDA, R.T.; BEDNARSKI, R.M. Manual de Anestesia Veterinária. 3. ed. Porto Alegre: Artmed, 2001, 432 p.

PUROHIT,N.R.; CHOUDHARY, R.J.; CHOUDAN, D.S. Abomasal impaction in a cow. Mod. Vet. Pract., v. 68, n. 5, p. 308, 1987.

RADOSTITS, O.M.; GAY, C.C.;HINCHCLIFF,K.W.; CONSTABLE,P.D. (Eds.). Veterinary Medicine: A textbook of the diseases of cattle, horses, sheep, pigs and goats. 10. ed. Edinburgh: W.B. Saunders, 2007. p. 2156.

RIET-CORREA, F.; SCHILD, A.L.; LEMOS, R.A.A.; BORGES, J.R.J. Doenças de Ruminantes e Equídeos. 3. ed. Santa Maria: Pallotti, 2007.

SAINT JEAN, G.; ANDERSON, D. Abomasal impactions in cattle. In: HOWARD, J.L.; SMITH, R.A. (Eds.). Current Veterinary Therapy: Food animal practice. Philadelphia: W.B. Saunders, 1999. v. 4, p. 532-533.
SILVA, R.A.C.; ARCURI, P.B.; D'AGOSTO, M.T. et al. Perfil das populações de

protozoários ciliados do rúmen de vacas não lactantes recebendo dietas ricas em

taninos. In: SEMANADE BIOLOGIA, 29. MOSTRADE PRODUÇÃO CIENTÍFICA DA UNIVERSIDADE FEDERAL DE JUIZ DE FORA, 12., Juiz de Fora, MG. Anais ... Juiz de Fora, MG: UFJF, 2006. p. 186-189.

SIMKINS,K.M.; NAGELE,M.J. Omasal and abomasal impaction inbeefsuckler cows. Vet. Rec., v.141, n. 1, p. 466-468, 1997.

SMITH, B.P. (Ed.).Tratado de Medicina Interna de Grandes Animais. 3. ed. São Paulo: Manole, 1993. p. 763-765.

TRENT, A.M. Surgery of the abomasums. In: Fubini, S.L.; Ducharme, N.G. (Eds.). Farm Animal Surgery. St Louis: W.B. Saunders, 2004. p. 196-240.

TURNER, A.S.; MCILWRAITH, C.W. Técnicas Cirúrgicas em Animais de Grande Porte. São Paulo: Roca, 2002. 341 p.

VAN SOEST, P.J. Nutritional ecology of the ruminant. 2 ed. Ithaca: Cornell University

Press, 1994. 476 p.

WHITLOCK, R. Vagal indigestion. In: HOWARD,J.L.; SMITH,R.A. (Eds.). Current Veterinary Therapy: Food animal practice. Philadelphia: W.B. Saunders, 1999. v. 4, p. 517-522.

WITTEK, T.; CONSTABLE,P.D.; MORIND.E. Abomasal impaction in Holstein-Friesian cows: 80 cases (1980-2003). J. Am. Vet. Med. Assoc., v. 227, n. 2, p. 287-291, 2005. 